\title{
Collective Identity Construction in International Collaborations
}

\author{
Ying Zhang* \\ (*corresponding author) \\ University of Strathclyde Business School \\ Department of Work, Employment and Organisation \\ 199 Cathedral Street, Glasgow, G4 0QU, UK \\ E:y.zhang@strath.ac.uk
}

Chris Huxham

University of Strathclyde Business School

199 Cathedral Street, Glasgow, G4 0QU, UK

E:chris.huxham@strath.ac.uk

Accepted version: September, 2019

Forthcoming in: Journal of General Management 


\title{
Collective Identity Construction in International Collaborations
}

\begin{abstract}
This paper explores the dynamic processes of collective identity formation among the participating organizational members in inter-organizational collaborations that cross national boundaries. A longitudinal, qualitative multi-case study research approach was adopted in the empirical investigation of collective identity in three international business collaborations that involve a Sino-British strategic partnership, a Sino-Australian and a Sino-Polish joint venture. Based on the analyses of the data collected from in-depth interviews, participant observation and archival materials, a theoretical framework of collective identity (re)formation is developed. It suggests that two inseparable elements (states and processes) constitute a cyclic and enduring process of collective identity formation through partners' orchestrating discursive resources involving a common sense of 'we-ness'. The shifts between various states are driven by partners' processes of negotiation, integration, solidification and reformation of collective identity. A deconstruction process may also emerge, giving rise to the termination of the collaborative relationship. The research presented in this article advances the understanding of collective identity formation in the field of organizational identity by extending the discursive perspective of collective identity into the context of inter-organizational collaborations that cross national borders. This research also provides further empirical evidence on the active role played by organizational members in the use of cultural narratives as strategic resources to express their identity beliefs, which differs from the deterministic view of culture in shaping organizational members' behaviors.
\end{abstract}


Keywords: international collaboration, collective identity, identity work, collective identity work, inter-organizational relationships, collaborative advantage 


\section{Collective Identity Construction in International Collaborations}

The notion of collective identity has acquired increasing prominence within organization theory as researchers have investigated how it shapes, sustains and steers organizational behavior (Patvardhan et al., 2015; Wry et al., 2011). Collective identity has been studied in various organizational contexts from individual organizations (Brown and Humphreys, 2002; Powell and Baker, 2017) to inter-organizational collaborations (Hardy et al., 2005; Koschmann, 2013; Öberg, 2016; Patvardhan et al., 2015; Rometsch and Sydow, 2006; Wry et al., 2011) which are defined as distinct organizational forms consisting of partnering organizations that come together to leverage resources and achieve strategic goals that could not be realized alone (Beech and Huxham, 2003; Hardy et al., 2005). In such an interorganizational collaboration context, collective identity has been defined as "we-ness" of a group (Hardy et al., 2005), underscoring the "similarities or shared attributes around which group members coalesce" (Cerulo, 1997: 386).

Collective identity has been regarded as critical in sustaining collaborative relationships in inter-organizational collaborations (Hardy et al., 2005; Koschmann, 2013; Maguire and Hardy, 2005; Wry et al., 2011; Zhang and Huxham, 2009). It can create legitimacy (Wry et al., 2011) and social capital (Ibarra et al., 2005) which are deemed as essential for supporting inter-organizational relationships (Koschmann, 2013). Collective identity can also induce collective action (Wry et al., 2011) and motivate partnering organizations to commit to collective action (Fiol and Romanelli, 2012; Zhang and Huxham, 2009). Additionally, collective identity can influence how partnering organizational members make sense of and adapt to organizational change (Patvardhan et al., 2015; Ybema et al., 2012). Yet, achieving a collective identity is regarded as a complex phenomenon because of 
the complications involving the coordination of partnering organizations with competing goals and interests (Koschmann, 2013; Patvardhan et al., 2015).

Extant studies on collective identity often draw upon conventional notions of organizational identity which is a well-established concept in the organizational and management literature (Koschmann, 2013; Patvardhan et al., 2015; Wry et al., 2011). Organizational identity is defined as what is central, distinctive, and enduring about an organization (Albert and Whetten, 1985). Much of this work conceptualizes organizational identity as a cognitive construct (Pratt, 2003; Whetten, 2006). From a discursive perspective, however, the study of collective identity in inter-organizational collaborations calls for a departure from conventional notions of organizational identity for two main reasons. First, inter-organizational collaborations are regarded as dynamic and ambiguous contexts, which suggests collective identity is fluid rather than enduring (Ellis and Ybema, 2010; Hardy et al., 2005). Second, there is an upsurge of scholarly attention to the conceptualization of collective identity as a process that is recursively constructed and reconstructed through discursive practice, rather than a cognitive belief held by organizational members (Brown, 2006; Brown and Humphreys, 2002; Ellis and Ybema, 2010; Hardy et al., 2005; Koschmann, 2013; Ybema, 2010).

Such a discursive approach to collective identity is represented by the notion of collective identity work which stresses the performative nature of collective identity narratives that are "speech-acts" constitutive of organizational realities (Brown, 2006: 734). From this perspective, collective identity is a discursive construct, embedded in the collective identity stories that, for instance, organizational members share in their everyday conversations and encode onto organizational websites, magazines, or historical accounts 
(Brown, 2006: 734). A focus on collective identity work helps direct analytic attention towards how participating members recursively make sense of themselves in relation to others (Ellis and Ybema, 2010; Ybema et al., 2012). Collectively, identity work can therefore be perceived as a matter of discursively enacting relationships of "similarity and difference" (Ellis and Ybema, 2010: 280), a state of forming and becoming rather than being (Tsoukas and Chia, 2002).

Recently, research has moved beyond investigating the consequences of collective identity in inter-organizational collaborations (Hardy et al., 2005) to analyzing the processes of collective identity work (e.g. Ellis and Ybema, 2010; Patvardhan et al., 2015; Ybema et al., 2012). Extant studies predominantly focus on inter-organizational collaborations within one national context (e.g. Ellis and Ybema, 2010; Koschmann, 2013; Patvardhan et al., 2015). For instance, drawing from a communicative model of organizational constitution, Koschmann (2013) empirically investigates the emergence of collective identity based on a case study of a social services inter-organizational collaboration in the United States. Patvardhan et al. (2015) examine collective identity work of a nascent academic field based on the grounded study of 46 information schools in the United States.

However, collective identity work remains largely under-researched in the context of international collaborations (Vaara et al., 2003; Ybema et al., 2012) which are interorganizational collaborative arrangements that cross national borders such as international joint ventures (IJVs), networks, strategic partnerships and alliances (Luo, 2002; Zhang and Huxham, 2009). Compared with domestic inter-organizational collaborations, international collaborations often invoke a thicker notion of cultural identities among partnering organizational members due to the cross-cultural relationships with their counterparts 
(Ybema and Byun, 2009; Ybema et al., 2012). Competition and power differentiation between collaborating organizations tend to intensify participating members' awareness of their own culture and their dissociation from the "cultural other" (Ybema et al., 2012: 50). As a result, transnational conflicts may emerge, for instance, in IJVs (Brannen and Salk, 2000), international projects (van Marrewijk, 2010) and mergers and acquisitions (Vaara et al., 2003). If left unresolved, such transnational conflicts tend to give rise to collaborative inertia (Huxham and Vangen, 2005; Vangen, 2017). Ybema et al. (2012) demonstrate the critical role of collective identity work in international collaborative relationship-building based on an ethnographic case study of an international collaboration in the third sector between a Dutch non-governmental organization and their Southern partners. Their findings suggest that participating members often adopt discursive strategies in forming collective identity to break down the hierarchical and cultural divides between themselves and others (ibid). They also call for further study to investigate collective identity work in other types of international collaborations.

The purpose of this study is to examine the processes of collective identity work in international business collaborations, using a discursive approach to collective identity (Brown, 2006; Hardy et al., 2005) as a theoretical basis for explanation. Based on the longitudinal investigation of three international business collaborations through qualitative interviews, participant observations and archival materials, this study unravels the mechanisms through which collective identity forms and reforms in the discursive acts of partnering organizational members. Accordingly, this study makes a number of important contributions to both the fields of organizational identity and inter-organizational relations. First, it adds to our understanding of collective identity formation at the inter-organizational 
level, which is the key theme in current organizational identity research (Patvardhan et al., 2015; Wry et al., 2011). By theorizing collective identity from a discursive perspective, this study continues the tradition of the linguistic turn (Brown, 2006) by challenging the "subjective-objective dualisms" that are prevalent in organizational research (Koschmann, 2013: 63). Second, previous research often examines collective identity formation within one national context (Ellis and Ybema, 2010; Koschmann, 2013; Öberg, 2016; Patvardhan et al., 2015; Wry et al., 2011), whereas this study looks at collective identity formation in a transnational context. It underlies the influence of cultural narratives in the shaping of collective identity (Ybema et al., 2012). Third, this study extends the inter-organizational relations literature (Huxham and Vangen, 2005; Vangen, 2017) on the processual understanding of collaborative relationships through the lens of collective identity work. International collaborations often magnify issues of diverse partnering organizational identities and the need for a collective identity at the inter-organizational level for partners' development of social relationships and mutual agreements. Therefore, this study extends the microscopic understanding of inter-organizational relations (Beech and Huxham, 2003; Hardy et al., 2005; Maguire and Hardy, 2005) through the discursive approach to collective identity.

The rest of the article is structured as follows. It will begin with a review of extant literature on collective identity and collective identity in an international collaboration context. Then the qualitative research approach adopted in the study will be explained. This is followed by the presentation of the empirical findings encapsulated by a model of collective identity construction in international collaborations. This article concludes with a discussion of the research contributions and implications for future research. 


\section{Theoretical Background}

\section{Collective identity}

In organizational and management research, the notion of collective identity is grounded in the study of organizational identity that has a long and diverse history (Albert et al., 2000; He and Brown, 2013; Koschmann, 2013). Taking as their point of origin Albert and Whetten's (1985) seminal definition that an organization's identity is what is central, distinctive, and enduring about it, collective identity has received increasing attention from scholars (Brown, 2006; Brown and Humphreys, 2002; Patvardhan et al., 2015). There is, nevertheless, considerable scope for divergent interpretations of dynamism and change in collective identities (Brown, 2006; Koschmann, 2013; Patvardhan et al., 2015). Extant studies on collective identity often draw upon two theoretical perspectives: the institutional perspective (Whetten, 2006; Wry et al., 2011) and the discursive perspective (Brown, 2006; Hardy et al., 2005). Table 1 summarizes these.

Insert Table 1 about here

The institutional perspective on collective identity highlights the set of organizational claims to a "social category" (Glynn, 2008: 419) such as industry or sector membership (Rao et al., 2000). Building on work in the institutional tradition (DiMaggio and Powell, 1983), scholars emphasize the central-enduring-distinctive attributes of an organization in the eyes of its members (Whetten, 2006). Proponents of this perspective tend to underscore the cognitive processes of sensegiving as a function of collective identities, viewing formal organizational claims as principles guiding how organizational members should behave and/or how organizational stakeholders should relate to them (Whetten, 2006; Wry et al., 
2011). Accordingly, organizational leaders and/or spokespersons tend to utilize formal identity claims to influence how internal and external audiences define and perceive the organization, by means of positioning it within a range of "legitimate social categories" (Ravasi and Schultz, 2006: 435). However, this institutional perspective tends to overlook the meanings underneath such organizational claims and the processes through which such meanings take shape (Patvardhan et al., 2015). It thus downplays collective identity formation processes and offers an incomplete understanding of identity (ibid).

The discursive perspective on collective identity is argued to provide more insightful understanding of the processes through which organizational members arrive at mutual agreement upon collective organizational claims (Hardy et al., 2005; Patvardhan et al., 2015). Drawing from a social constructionist approach to identity (Brown, 2006; Sveningsson and Alvesson, 2003), proponents of the discursive perspective embrace the notion of identity work that emphasizes the fluidity and "on-going struggles around creating a sense of self and providing temporary answers to the question 'who am I' (or 'who are we') and 'what do I (we) stand for?'”(Sveningsson and Alvesson, 2003: 1164). Identity work is often triggered by "specific events, encounters, transitions, surprises, as well as more constant strains" and it is "grounded in at least a minimal amount of self-doubt and self-openness, typically contingent upon a mix of psychological-existential worry and the skepticism or inconsistencies faced in encounters with others or with our images of them" (Alvesson and Willmott, 2002 cited in Alvesson, 2010: 201). This view of identity also implies the continuity of self-images (across time and space) (Hatch and Schultz, 2002) as interpreted reflexively by the agent at different layers of self-understanding (Giddens, 1991). 
Identity work has predominantly been studied at the individual (Beech, 2011; Collinson, 2003; Sveningsson and Alvesson, 2003; Thomas and Linstead, 2002; Watson, 2008) and group level (Alvesson and Kärreman, 2007; Thornborrow and Brown, 2009) within the context of a single organization. Identity work at the level of collective organizations - i.e., collective identity work (Patvardhan et al., 2015) - in an interorganizational context, especially in international collaborations, still lacks empirical examination. Building on the notion of collective identity work (Hardy et al., 2005; Patvardhan et al., 2015), this research will focus on the examination of identity work at the level of collective organizations in transnational contexts which are termed as international collaborations (Luo, 2002; Zhang and Huxham, 2009). The literature on collective identity work in international collaborations will be reviewed next.

\section{Collective Identity in International Collaborations}

International collaborations are examples of complex encounters that often trigger collective identity work amongst partnering organizational members (Vaara et al., 2003; Ybema and Byun, 2009; Ybema et al., 2012). In inter-organizational relationship contexts, collective identity has been defined as the we-ness of a group (Cerulo, 1997), stressing the similarities or shared attributes around which group members coalesce (Hardy et al., 2005). The process of group members' constructing similarities or shared attributes suggests that collective identity is discursive by nature, produced in and through conversations. According to Hardy et al (2005: 62), collective identity can be regarded as a "linguistically produced object" revealed in talk and other forms of text, rather than as a set of cognitive ideas held in members' minds. When partners in collaboration discursively construct a collective identity, they construct a discursive object that associates themselves as some form of collective, 
rather than merely as a group of disconnected representatives from different collaborating organizations. This collective identity 'names' the group by giving an identity that is meaningful to its members and to its stakeholders, and it is mutually shared, in the sense that members collectively engage in the discursive practices that produce and reproduce it over time (Brown, 2006).

The relationship between international collaborating partners can become challenging because of their differences regarding, for example, national cultures and working routines (see, for example, Salk and Brannen, 2000; Sirmon and Lane, 2004). Cultural distance is a widely used concept for differentiating one group of people from another (Hall, 1976; Hofstede, 1980; Trompenaars and Hampden-Turner, 1997). For instance, Hofstede (1980) delineates members in an individualistic society as self-centered, calculative, competitive rather than co-operative, having a low need for dependency on others; members in a collectivistic society, however, are often viewed as co-operative, highly loyal to the organization and prioritizing the moralistic values of group efforts and rewards. Hall (1976) characterizes high-context as a culture with intimate relationships among people and an implicit communication style with simple messages but deep meanings; and low-context culture features as individualized and fragmented relationships among people, with explicit and non-personal communication styles. Cultural distance may lead to the salience of group identities (i.e., in-group preferences and out-group distinctions) among multinational management teams (e.g., Li et al., 2002; Pearce, 2000). Empirical studies have yet to confirm how these salient group identities/categorizations are formed by individual and collective members in international collaborative practice (Salk and Brannen, 2000). There is also a lack of studies exploring how cultural distance can be used as symbolic resources in 
organizational members' "self-other identity talk" (Ybema and Byun, 2009: 341) for the purpose of in-group and out-group boundary drawing (Salk and Brannen, 2000; Vaara et al., 2003).

Mistrust and conflicts may emerge between partners when there are constant distinctions between 'who they are' and 'who others are' (Salk and Shenkar, 2001). Differences in natural languages and professional jargon can intensify this complex relationship (Vaara et al., 2005). How managers comprehend each other's language use can also impact on their perceptions and behaviors toward each other (Hardy et al., 2005; Maguire and Hardy, 2005). Interpreters are often employed by parent organizations to facilitate the assigned managers' understanding of their counterparts. The role of interpreters is seen as important in understanding the collaborative processes (Hoon-Halbauer, 1999) because they are directly or indirectly involved in relationship-building among assigned managers.

Zhang and Huxham (2009) examine identity work in relation to trust building with the data drawn from an IJV. Their findings indicate that in order to initiate and sustain trust it is crucial for assigned managers and other participants to show 'deference action' towards the collective identity construction and maintain 'identity fit' with each other. They develop the notion of 'identity characters' to refer to the use of discursive resources - primarily in the linguistic form of nouns (roles/titles/names such as manager, accountant and interpreter) and adjectives (manifested attributes such as sociable, powerful and easygoing) - to describe implicit perceptions of participants' identities. Based on this notion, Zhang and Huxham (2009) also develop the notion of 'collective identity characters' (CICs) which specifically refers to the 'identity characters' that are mutually shared by partners. For instance, in a 
newly established IJV (50-50 equity share between partners) in manufacturing sportswear, collaborating partners might construct 'new sportswear company' and 'equal, diverse and innovative' as the CICs that both parties mutually share when constructing their collective identity for the IJV. CICs can be embodied in various forms of discursive practice such as texts and speeches publicized both externally to the environment (e.g., the name, mission statement and annual report of the collaboration) and internally to the collaborating partners and shareholders (e.g., contracts, minutes of meetings, and memoranda of understanding), unpublicized texts which are known to only one or a few collaborating parties but not all involved (e.g., negotiation documents), and daily conversations between participants (Zhang and Huxham, 2009). CICs can thus be regarded as detailed manifestations of the attributes of collective identity and a set of CICs constitute what collective identity is about. These notions of 'identity characters' and CICs are helpful in the conceptualization of collective identity construction in international collaborations in that they help to clarify the role of language in the formation of identity (Fiol, 2002; Vaara et al., 2005) and capture the process dynamics that contribute to the state of group differentiation (Pearce, 2000).

In this study, the notions of identity characters - and CICs in particular - will be adopted as foundation concepts for the analysis that follows. At least a part of the reason why few researchers have examined collective identity work in international collaborations is that identity is predominantly studied quantitatively to test pre-established models of social identities (Li et al., 2002; Pearce, 2000) rather than to delve into the social processes to which the notion of identity relates (Alvesson, 2010; Humphreys and Brown, 2002; Sveningsson and Alvesson, 2003). Existing studies largely focus on the salience of identity; that is, on the state of group differentiation ('us' versus ‘them') (Pearce, 2000; Salk and Shenkar, 2001). 
Yet, the process-oriented, discursive perspective on collective identity work is still rare (Brown, 2006; Hardy et al., 2005). Maguire and Hardy (2005) explore the relations between the process of identity construction and strategy-making by conducting a case study of a collaborative strategy implemented by the community organizations and pharmaceutical companies concerned with Canadian HIV/AIDS treatment. Beech and Huxham (2003) develop a model of individual identity construction in collaborative situations with the data drawn from a collaborative arrangement concerned with health promotion in the UK. Their findings suggest that identity is constructed as a complex mêlée of cycles in interaction which subsequently impact on relationship dynamics between the collaborating participants. Ellis and Ybema (2010) examine the discursive identity work of marketing managers involved in inter-organizational relationships (IOR) within industrial supply chains. Their study suggests that IOR managers can be seen as 'boundary bricoleurs' who oscillate between an inclusive and exclusive 'us' and 'articulate embracing yet distinctive identities vis-à-vis other network actors' (Ellis and Ybema, 2010: 279). However, none of these studies extends the examination to collective identity construction between the collaborating participants who represent organizations from different nations. This research endeavors to fill the gap by focusing on the exploration of collective identity construction by participants in international collaborative settings.

\section{Research Approach}

In light of the potential for competing interpretations and meanings in the research field, this study adopted a longitudinal, multi-case study research approach (Eisenhardt, 1991) combined with multiple research methods (Brewer and Hunter, 1989) to interpret social reality (Denzin and Lincoln, 1998). Longitudinal research design has been widely 
adopted in identity studies (e.g., Patvardhan et al., 2015; Pratt, 2000; Ravasi and Schultz, 2006) because it is regarded as effective for investigating identity-related process questions (Ravasi and Schultz, 2006). The multi-case study research approach allows the development of emergent theory which can be more generalizable and better grounded than theory from a single-case study approach (Davis et al., 2007). This research approach also permits a replication logic in which multiple cases are "discrete experiments" that confirm or disconfirm the emerging theory (Eisenhardt and Graebner, 2007: 25).

The field investigation was conducted in three selected cases called, respectively, Gelstom, Telstom and Shelstom, which are pseudonyms given to the investigated international collaborations. Gelstom was a strategic engineering partnership between a wholly-owned subsidiary of a UK-based engineering company (Britco) and a Chinese-based state-owned engineering company (Chinco1). Britco and Chinco1 maintained a longstanding partnership of almost 30 years. It was a typical Western-Eastern partnership in that Britco provided Chinco1 with technologies and know-how, and Chinco1 helped Britco with the operations in the Chinese local market and business networks (Yan and Gray, 1994). Gelstom faced a turning point at the time of field entry in that Britco was trying to initiate a proposal to develop the partnership into an equity JV with Chinco1. The negotiation about this - as well as the subsequent contractual assurance - was still in progress at the time of the field entry regarding the possibility of starting such a JV.

Telstom was a JV between an Australian building material company (Ausco) and a state-owned Chinese construction company (Chinco2) in the construction and building materials industry. It was established in 1994 in Tianjin with the equity share dominated (around 60\%) by Ausco. In 2003, in order to have complete control of the JV, Ausco bought 
$99 \%$ of the equity share and left $1 \%$ for Chinco 2 and many assigned managers from Chinco 2 left Telstom. Despite the loss of control in Telstom, Chinco2 still wanted to play some role in Telstom's management in order to be perceived by the external environment in China as having a connection with a foreign investment.

Shelstom was a shipping JV founded by the Chinese and Polish government in the 1950s. It was regarded as one of the earliest JVs in China. The equity was equally shared, by the Chinese state-owned enterprise (Chinco3) and a Polish company (Polco) in the shipping industry. Shelstom has maintained its collaborative form for more than 60 years.

\section{Data Collection}

Data collection was accomplished partly through interviews (Jones, 2004; Silverman, 1993) and participant observation (Junker, 2004) and partly through archival materials. The field investigation spanned from July 2005 to August 2016. Table 2 presents a detailed list of all data sources collected for this research. In particular, interviews and participant observation were conducted from July 2005 to October 2006. Archival data were collected from July 2005 to August 2016. In Gelstom, unexpected confidentiality concerns from the Chinese senior managers led to restricted access and only a single interview with one of the British managers actively involved in the collaboration was possible. However, substantial longitudinal archival data (e.g., field investigation reports, financial reports, company reports, minutes of meetings, memoranda of understanding, and e-mails between Chinese and British managers were obtained from July 2005 to August 2016 and, after the interview, email communication was maintained with the interviewed manager on a regular basis to obtain key documents and keep the conversation on-going in respect of developments in the collaborative relationship. The field study in Gelstom served as a good basis for refining in- 
depth interview questions and improving other data collection techniques in the investigation of Telstom and Shelstom.

Insert Table 2 about here

In Telstom and Shelstom, 35 in-depth interviews were conducted (19 interviews in Telstom and 16 in Shelstom) between July 2005 and October 2006 with the middle and senior managers assigned by each parent company. The interviews were conducted in the JV premises of Telstom and Shelstom based in China. The in-depth interview questions were designed with the aim to stimulate respondents into conversation about their collective identity work from the practical experiences of their engagement in international collaborations. English was not the first language for many of the interview respondents. For Chinese respondents, the interview questions, which were originally designed in English, were translated to Chinese by a professional bilingual interpreter (English - Chinese) and then blindly back-translated (Brislin, 1986) to English by another professional bilingual interpreter (English - Chinese) in order to validate the conceptual equivalence (Schaffer and Riordan, 2003) of the constructs in the interviews. The discrepancies between the original and translated constructs in the interview questions were visited and revisions were made to achieve the consistency of these constructs in both Chinese and English. Before translating for this research project, both of the interpreters had gained extensive working experience on cross-cultural communications in business collaborations and were proficient in both English and Chinese languages. In Shelstom, participants from Polco chose English for their interviews; although this was not their native language, English was the official communicating language in the collaboration. 
In addition to interviews, the first author conducted participant observation (Hammersley and Atkinson, 1983) in Telstom and Shelstom with the aim of examining the dynamic process of collective identity work among the collaborating partners. In both cases, she was assigned to participate in the secretarial unit and her participant role as a researcher was explicitly stated to the managers and employees in advance. The detailed work involved transferring messages from other departments to the managers, organizing meetings for managers, and co-operating with other secretaries to transfer information from managers to different departments. Her role was mainly to assist other secretaries and her duties shifted flexibly according to other secretaries' availability. Such flexibility of working in the researched organizations allowed the researcher to walk around and talk to people quite easily. It also enabled the researcher to gain the trust of co-workers and ask questions that may otherwise seem unusual coming from a co-worker (Pratt, 2000). This participant role lasted seven days in each of the settings between July and August 2005. Apart from having open conversations with the employees in Telstom and Shelstom, she was allowed to record some meetings and daily events and thus capture partners' dynamic interactions in the research settings. She also made field notes and diaries of what was observed in both Telstom and Shelstom on a daily basis. The validity of the observational notes and diaries was constantly checked with other data sources, such as interviews and archival data (Pratt, 2000). The findings from the observational notes and interviews were also emailed to the observation and interview respondents to solicit their feedback. This validation process helped clarify the final outcome of the research analysis (Koschmann, 2013) and ensure trustworthiness (Lincoln and Guba, 1985) 
Furthermore, longitudinal archival data were collected from the three cases - which spanned over 11 years - to investigate the processes and changes of collective identity in international collaborations. The sources for archival data included company reports, memoranda of understanding, minutes, email exchanges among partners, and other related internal and external communication materials. These archival data enabled the tracking of the evolving identity claims (Ravasi and Schultz, 2006) from the collaborating partners involved in the three cases. The archival data also helped to triangulate the insights gathered from both the interviews and participant observation, and, thereby, mitigate possible "retrospective bias" in the interviews (Patvardhan et al., 2015: 410).

\section{Data Coding and Analysis}

The data gathered from interviews, participant observation, and archival materials were systematically visited and revisited in order not to lose any expressions and insights in relation to collective identity themes. First, the first-order concepts (i.e., language used by informants) (Corley and Gioia, 2004) were identified concerning CICs in terms of reviewing every interview transcript sentence by sentence to highlight any expression in noun and adjective forms such as personal characteristics (e.g., trustworthy, stern and humorous), roles and titles (e.g., accountant, consultant and manager), and perceptions of 'we-ness' (e.g., we, us and so forth) (e.g., optimistic, worrying and confused). Attention was also paid to the use of verbs because some of the verbs have equivalent nouns and/or adjectives. For example, the use of a verb like 'trust' in the expression 'the Chinese partners also trusted the Australian partners' (extracted from an interview transcript in the Telstom case) can be converted to the adjective form of 'trustable' or 'trusted' to describe the identity character of the Australian partners in the eyes of their Chinese counterparts. Notes were made beside the highlighted 
expressions based on the reflections of the participant-observer in Telstom and Shelstom.

Next, second-order concepts were generated (i.e., the 'theories' a researcher uses to organize and explain the 'facts' of an ethnographic investigation) (Maanen, 1979: 540), wherein the relationships between and among the first-order concepts across the three cases were inspected, which gave rise to the categorization of the higher order themes on CICs. Furthermore, similar themes were congregated into two overarching elements that constitute the basis of the emergent framework. The techniques used were by no means linear but "formed a "recursive, process-oriented, analytic procedure" (Locke, 1996: 240) that continued until we had a clear grasp of the emerging theoretical relationships' and additional interviews and supporting documents "failed to reveal new data relationships" (Corley and Gioia, 2004: 183-184). During the data analysis period, both the first and second author also presented the concepts and supporting data to colleagues who offered valuable perspectives that helped consolidate the concepts developed here. To illustrate the second-order concepts, quotations were used from the transcripts and documents; occasionally some details have been concealed for confidentiality purposes. Pseudonyms are used throughout.

\section{A Model of Collective Identity Work in International Collaborations}

The investigation of the Gelstom, Telstom and Shelstom settings suggests that two inseparable elements - states and processes - constitute a cyclic and enduring process of collective identity work in which cultural issues are used discursively by participating organizational members. The processes of collective identity work are encapsulated from the discursive practice of organizational members who do not explicitly verbalize 'identity issues' but rather perform identity work as part of the day-to-day business of making collaboration happen. These elements were captured through a model of collective identity 
work which is presented in Figure 1. In the following elaboration of the model, the term 'partners' is used to refer to the participating organizations and 'participants/members' to refer to the individuals involved in an international collaboration.

Insert Figure 1 about here

\section{States of Collective Identity Development}

The examination of the three cases suggests that CICs are ascribed by collaborating partners both unilaterally (i.e., by members of just one of the partners defining for themselves the nature of the collective identity) and mutually (i.e., by members of all partners jointly defining the collective identity). When ascribed unilaterally, CICs tend to be identified, reidentified and adapted according to the situations involved. When mutually ascribed, they tend to be identified, re-identified, crystallized, and, under certain circumstances, disidentified. Thus CICs occur in a range of different states of collective identity development, and culture is often used as a discursive resource by participants to justify these states (see Table 3).

Insert Table 3 about here

(Re) identified Unilaterally Ascribed CICs. Before proposing a collective identity to the counterpart(s), each partner tends to form a one-sided description of what a common sense of 'we-ness' is about. This generates identified, unilaterally ascribed CICs (UACICs). UACICs can also become re-identified when the partner changes the nature of the common sense of 'we-ness' in its one-sided description. The state of re-identified UACICs differs 
from identified ones in terms of the shifted nature of CICs ascribed. An example of this can be found in an interview comment from the Gelstom case:

'Sometimes we say we want 50-50 JV, sometimes we say to split into 60-40. I think ultimately we would want $60-40$, and to grow that into almost owning that company... we believe the main reason is typical Scottish mentality - a lot of money but we want a good deal' (BritcoSM1 $\left.{ }^{1}\right)$.

These identified (50-50) and re-identified (60-40) UACICs occurred at the time when Britco and Chinco1 had established a long term strategic partnership (since the 1980s). The reason for the UACICs shift was explained by the Senior Manager as 'Scottish mentality' with particular focus on obtaining a good bargaining result from the JV negotiation. It suggests that national cultural attributes can be discursively used by participants to explain a shift from the identified to re-identified state.

Adapted Unilaterally Ascribed CICs. With the increase of activities among partners, each partner may find that its one-sided description is incongruent with the description from its counterpart(s). That is, there may be incompatibility between the (re)identified UACICs from each partner. This can potentially impede the development of collaborative relationships if the (re)identified UACICs are in conflict among partners. For example, in Gelstom, if both Britco and Chinco1 had proposed their (re)identified UACIC to each other as ' $60-40$ ' or 'majority-minority' share mode rather than ' $50-50$ ', it is likely that the collaboration would have faced a standoff because of their disagreement on the nature of the common sense of 'we-ness'. This standoff situation was further supported by Britco's strategic report that was published in 2013. In the strategic report, it was stated that 'there was still disagreement [between Britco and Chinco1] on the equity share of the JV'. Britco's senior management team proposed to 'rethink of the JV strategy in China [with Chinco1]' by 'keeping the 
existing strategic partnership agreement with Chinco1'. Such statement can be regarded an example of Britco's adapted UACICs.

Adapted UACICs come into being when a partner changes its UACICs in order to be congruent with those of its counterpart(s). There is a similarity between adapted and reidentified UACICs in terms of the shifted nature of the common sense of 'we-ness'. However, there is a fundamental difference between the two states regarding the shifted UACICs from one partner: the re-identified state emphasizes the voluntary orientation without the necessity of taking any counterpart's UACICs into consideration; whereas, the adapted state focuses on the accommodating orientation to fit the UACICs from the counterpart(s).

Another example of adapted UACICs can be found in the case of Telstom on the issue of Ausco's change of its proposed accounting practice in order to be congruent with that of Chinco2. According to a senior Ausco manager, Ausco initially formed one of the UACIC's as a 'good cash flow state' which focused on the standardization of its own accounting system into Telstom, as indicated by the following interview comment:

'...Telstom should be in a good cash flow state. We could directly apply the headquarters' accounting system here. That was what we thought initially...' (AuscoSM3).

However, this UACIC was incongruent with one of Chinco2's. The senior manager further explained this and Ausco's adapted UACIC as follows:

'...they (Chinco2) suggested we tolerate the triangle debt problem. It's a special phenomenon in China. The clients often delay their payments to the manufacturers, which results in the manufacturers' cash flow problem. Manufacturers also find it difficult to make payments to their suppliers. This phenomenon doesn't exist in Australia and other western countries... So 
in (Ausco's) accounting system, there was no such calculation...Later we took (Chinco2's)

advice and made some adjustment to Telstom's accounting system...' (AuscoSM3).

Ausco adapted the UACIC 'good cash flow state' to 'tolerating the triangle debt' in order to be compatible with Chinco2. The state of adapted UACICs implies that partners often need to localize the management practice implemented in their home countries to fit the peculiarities of the host country. The cultural distance underneath the accounting practice between Australia and China was used by the senior manager as a way of showing why Ausco's UACIC became adapted to fit the Chinese environment.

(Re)identified Mutually Ascribed CICs. Mutually ascribed CICs (MACICs) concern the congruence of certain UACICs between collaborating partners. As with UACICs, MACICs can be identified and re-identified at any stage of an international collaboration. The difference between identified and re-identified MACICs lies in the shifted nature of CICs ascribed. For example, in Gelstom, according to the memorandum of understanding, Britco and Chinco1 had established a long term strategic partnership in the 1980s. The MACIC was initially identified as 'co-production of Alpha-Series engines' as is evident from the interview comment and letter excerpt below:

'Our relationship (Britco and Chinco1) started in 1985 with the co-production of Alpha-Series engines...' (BritcoSM1);

'...the successful partnership between Chincol and Britco in the co-production of AlphaSeries engines became a good foundation for our further cooperation...' (Chinco1GM1 letter to Britco's management team).

This identified MACIC was re-identified 'co-production of Beta-Series engines' in 1996:

'...from 1996 onwards we (jointly) stopped the Alpha-Series engines and got involved in the co-production of Beta-Series...' (Britco SM1). 
Issues of cultural distance tend to be downplayed by partners in the discursive construction of MACICs because congruence is an essential feature for the merging of partners' UACICs. For example, Britco's Senior Manager 1 addressed the similarities between Britco and Chinco1 in the explanation of identified and re-identified MACICs: despite emphasizing cultural distance with the phrase 'Scottish mentality' (see earlier quotation), he seemed to deliberately eschew difference, focusing on the commonality between both companies:

'...I think it is not different on the technical side... as far as it is clear for the benefit of the partnership, it is not different.' (BritcoSM1).

Crystallized Mutually Ascribed CICs. Crystallized MACICs refer to a stable collective image that participants can attach themselves to, which helps to strengthen the participants' sense of belonging. Crystallized MACICs endure across a time span. For instance, in Gelstom, the MACIC 'partnership' in 'product applications' and 'customer services' had been crystallized for more than 20 years up to the time of our empirical investigation, as the following jointly signed document reveals:

'We had established a solid partnership since the 1980s in product applications and customer services...' (extracted from Britco-Chinco1 memorandum of understanding published in 2012).

Another example occurred in Shelstom. According to its 50-year anniversary company magazine published in 2005 , Shelstom had operated consistently since 1951 . The MACICs 'company operating scale' and 'Asia-Europe break bulk liner service' were crystallized by Chinco3 and Polco participants:

'We've defined Shelstom's consistent image. It is the same all the time including the company operation scale...' (PolcoGM2). 
'Shelstom does not change its corporate image because the core business is Asia-Europe break bulk liner service.' (Chinco3SM3).

These crystallized MACICs appeared again in the annual report and website of Shelstom in 2015 .

As with (re)identified MACICs, partners seem to extenuate the issues of cultural distance to maintain congruity in the form of crystallized MACICs. For instance, when explaining the crystallized MACIC 'company operating scale', a senior manager emphasized the congruence achieved by Polco and Chinco3 and played down the role of culture in collaboration:

'Both parties have such invisible mutual agreement (remaining the company operating scale) ... Culture is not an essential factor. The essential factor should be each other's benefits...Both parties need to extensively understand each other and unify our opinions. This is our common feature...' (Chinco3SM3).

Dis-identified Mutually Ascribed CICs. Although the processes of (re)identified and crystallized MACICs are enduring, there are occasions where the processes are no longer sustained, which give rise to dis-identified MACICs. When this occurs, the collaborative relationship will disintegrate. The key feature of dis-identified MACICs is that they are not part of the cyclic process of collective identity work and they are no longer going to be (re)identified and adapted. For example, in Gelstom a joint memorandum of understanding of JV formation was signed in August 2004; this can be viewed as the formation of the reidentified MACIC 'JV'. A senior manager from Britco was tasked to participate in the JV negotiation and communicate regularly with Chincol's members. He sent an email to colleagues following a meeting with Chincol's General Manager in November 2004. The senior manager commented that 'the incentive for Chincol to conclude a JV negotiation with 
Britco is unlikely', which suggests that the MACIC 'JV' was dis-identified by Chinco1. In December 2014, the Britico annual report suggested that they resumed the JV talk with Chincol but failed to achieve the JV agreement again. The main reason for this could be explained by the senior manager as Chincol's high dependence on the financial subsidy from the parent company:

'...The GM (of Chinco1) indicated that being a "highly subsidized company in a monopoly state power bureau", Chinco1 looked at 2-3 years of good growth/profitability. Therefore, the incentive for Chinco1 to conclude a JV negotiation with Britco at this stage is unlikely' (BritcoSM3 email to working colleagues in 2004).

Issues of cultural distance on collectivism versus individualism tend to be used by collaborating participants in the discursive construction of dis-identified MACICs. For instance, when explaining why the MACIC 'JV' became dis-identified by Chinco1, Senior Manager 1 commented that Chinco1's General Manager tended to be more paternalistic to the employees because of the prevailing collectivism ('communistic outlook') culture. Whereas, Britco's members were more individualistic with emphasis on 'profit' and 'money' rather than the maximization of benefits for employees:

'...there are cultural issues obviously...the different mentality of a Chinese business person ... slightly more, you know, social, socialist, communist outlook. You know they are not necessarily to profit... when they see a western company coming in and talking about, you know, "we will give you this product; it will make us more money", this kind of thing...' (BritcoSM1)

Although dis-identified MACICs may look like an end point for collective identity work, a relationship may, in practice, be renewed. For instance, further in the email to his working colleagues, Senior Manager 3 indicated that 'Britco should look for other potential 
JV partners or make a new JV proposal to Chincol in a few years' time'. This suggests that participants might seek to reinvigorate the cyclic process of collective identity work.

\section{Processes of Collective Identity Development}

Our investigation of the three studies suggests that the states of collective identity described above are reached through four key processes - (silent) negotiation, integration, solidification and reformation - that occur at different stages and in varying contexts over an international collaboration's lifetime. A process of deconstruction may also emerge, which terminates the collaborative relationship. Collaborating participants often actively maneuver the discursive resources of cultural distance to express their identity beliefs. These processes are summarized in Table 4.

Insert Table 4 about here

(Silent) Negotiation of Unilaterally Ascribed Collective Identity. The different aims and interests that partners have toward an international collaboration often result in divergence of their (re)identified UACICs. They can be transformed into adapted UACICs which are achieved through partners' negotiation of unilaterally ascribed collective identity. This negotiation process may be overt, involving all partners but it may also be silent, involving one partner's internal discussion that leads it to adapt without even referring to the other partner(s) directly.

Overt negotiation appears to be achieved through both direct and indirect communication. Direct communication involves partners' meetings and daily working practices. For example, in Telstom an Operations Manager from Chinco2 explained how the daily working practice with Ausco's members made Chinco2's members adapt their UACICs 
to be congruent with Ausco's. As he described in his interview, because of 'long experience of working as leaders in the Chinese state-owned enterprises', Chinco2's members initially identified a UACIC of Telstom as 'another state-owned enterprise' with a main feature being: 'no objection to leaders' opinions at meetings'. This UACIC was later adapted to be congruent with Ausco’s which was 'more open'. Joint meetings and Ausco’s members' daily working practice of inviting opinions from Chinco2's members contributed to the adaptation of Chinco2's UACIC:

‘...but they always asked for our views at meetings and during our daily work...we were impressed by their sincere attitudes...Later we realized that Telstom was more open and vibrant to us (than Chinco2). Seniority was not a big matter. Communication was much easier' (Chinco2OM1).

'...At the beginning, we found they (Chinco2's members) were very slow in responding to our proposals...Telstom should be more open in terms of communication...If we thought our values were more suitable for the company development, we usually persuaded the Chinese managers to accept them... of course, we also put the values into our actions to show everyone that we were serious about them' (AuscoGM8).

Indirect communication involves a third party's facilitation, usually through language interpreters who facilitate understandings between partners in the negotiation process. For example, in Telstom a Marketing Manager, who was hired locally for the JV, explained in her interview how her previous position as a personal assistant and language interpreter contributed to Ausco's adaptation of its UACIC to be congruent with Chinco2's. She recalled that when Telstom was initially established, some of Chinco2's managers received monthly payment from the JV without necessarily working there. This was mainly determined by the local Chinese labor policies. However, Ausco's members did not know of the policies and 
developed a UACIC on 'recruitment and redundancies' consistent with Ausco's own practice because they 'had the major share in Telstom and thus should have the control'. This dictated that those who did not work for Telstom should not be paid. The Marketing Manager further commented that with the facilitation of the interpreters and employees in Telstom, Ausco's members subsequently understood the local labor policies and made adaptations of its UACIC on 'recruitment and redundancies' to fit that of Chinco2.

Alongside the overt negotiation, silent negotiation (i.e., negotiation within one organization not heard by the members of a partner organization) was also prevalent in the discourse of the three cases. Email communication is a common mechanism for silent negotiation because of the convenience of information flow. For example, in Gelstom, Britco's members had an internal discussion about the 60-40/40-60 JV negotiation with Chinco1 participants mentioned above. A business development manager from Britco sent an email to colleagues tasked to participate in the JV and communicate regularly with members of Chinco1, making suggestions about how they should respond at the forthcoming negotiation meeting:

'...Y You could state disappointment at their (Chinco1's) position on initial shareholding (60\% Chinco1) but state that we could accept this at the start of the JV provided we have a clear and agreed route to increasing the share for Britco when the new plant is up and running...' (BritcoBDM2 email to colleagues in 2004).

This suggests that internal discussion among Britco's members led to the change of its identified UACIC ' $60 \%$ Britco' to the adapted one '40\% Britco' with an additional prerequisite intended ultimately to lead to the increase of Britco's shareholding.

Third party business consultants often play a mediating role in silent negotiation similar to a language interpreter's role in overt negotiation - in facilitating partners' towards 
collective identity development. For instance, later in the above email, a consultant was proposed as an advisory agent to assist Britco's members' understanding of the role of the Chinese government:

'...the JV is not only about Britco and Chinco1. The government also plays a role in it... Perhaps Jenny (business consultant to Britco) can advise on whether / how we should be programming a meeting for George (Britco Chief Executive) with a senior municipal / government official. Ultimately, if we are doing a deal with a state-owned body, we will want to ensure there is real political clout behind it...' (BritcoBDM2 email to colleagues in 2004). Expressions relating to cultural distance are often discursively used in partners' (silent) negotiation, which leads to divergent views about the unilaterally ascribed collective identity. The interview comment, above, from the Marketing Manager in Telstom can serve as an example. She described the 'cultural shock' faced by the Ausco members towards the payment scheme offered to those Chinco2's managers who did not actually work in the JV. The cultural distance lies in the collectivism versus individualism management practice between Chinco2 and Ausco members. Collectivism is often prevalent in Chinese stateowned enterprises like Chinco2. 'Iron bowl policy', which means a stable occupation and welfare for life, was still adopted by many of the Chinese state-owned enterprises. Under this policy, it was not surprising that some Chinco 2 members were still paid even though they did not work in Telstom. In contrast to Chincol's collectivism culture, individualism, which highlights the role of individuals' contributions to an organization, often prevails in western multinational corporations like Ausco. The Marketing Manager used cultural distance in her conversation to differentiate the UACICs held by Ausco and Chinco2 members and expressed her role as an interpreter to facilitate partners' mutual understanding. The group of interpreters and consultants are often well trained in terms of cross-cultural understandings. 
They can bring their expertise into the understanding of partners' UACICs and facilitate the change of their (re)identified UACICs to adapted ones.

Integration of Unilaterally Ascribed Collective Identity. The shift from adapted or (re)identified UACICs to (re)identified MACICs is often achieved by collaborating partners' integrating their unilaterally ascribed collective identity. First, the shift from adapted UACICs to (re)identified MACICs typically takes place in meetings and social events such as 'meals outside work'. For example, in the context of Telstom's triangle debt issue, mentioned previously:

'... we (Ausco's members) had lots of meetings with them (Chinco2's members) about it (triangle debt). We also had conversations outside work when we had meals together...We agreed on the change of the accounting system to tolerate the delay in payments from our clients...The meeting outcomes were published in the company magazine. So everyone would know what was going on' (AuscoSM3).

These activities contribute to partners' mutual understanding of how collective identity is perceived by each partner. When a MACIC is identified by all collaborating partners, a joint collective identity comes into place. This joint collective identity is often revealed to all members involved by means of organizational artifacts such as Telstom's ‘company magazine' which was published and circulated internally on a monthly basis

Issues of cultural distance regarding high- and low-context are often discursively used by participants to differentiate the use of meetings from social events in the integration of unilaterally ascribed collective identity. For instance, a senior manager from Chinco2 commented on the high-context culture in China through the use of informal social events such as 'meals' to establish 'guanxi' or personal relationships (Park and Luo, 2001) which are crucial for developing the collaborative relationship. This is different from the low- 
context culture favored by the Australian partner who preferred formal 'meetings' over 'meals':

'Nowadays, the Chinese company may get a partnership from the informal conversation. We even pay more attention to this way: being a Chinese, when you sit beside your partner, there is no need to talk about business. We should talk about friends, talk about our friendship. In view of the topic of our conversation today, we do not need to mention it until we leave. After our meal, our business could be done over a phone call once we are leaving the meal and sitting in the car. This is eastern culture. While for westerners, we need to discuss what benefit you can get and what I can get at meetings. If it is good for both parties, we will do afterwards. So these are the things approached from different angles...' (Chinco2SM2). Second, the shift from (re)identified UACICs to identified MACICs tends to be achieved through institutional interventions external to the participating organizations. Under certain circumstances, institutional forces can supersede the organization's will in the integration of unilaterally ascribed identity; the integration may not be necessarily preceded by the (silent) negotiation of unilaterally ascribed collective identity because the collective identity has already been chosen by external forces. For instance, in Shelstom, Chinco3 formed a re-identified UACIC as 'increase' of 'shipping routes' and Polco formed one as 'expansion' of 'shipping vessels', which suggested divergent foci on the development of Shelstom. There was no formal negotiation of the unilaterally ascribed collective identities but an identified MACIC ('Asia-Europe break bulk liner service') was given to both partners by their governments:

‘...in 1990s, both sides (Chinco3 and Polco) suggested some proposals for Shelstom’s development, like we (Polco) proposed the expansion of shipping vessels to them (Chinco3), and they also proposed the increase of shipping routes... We did not officially discuss these 
proposals between us but we consulted with our governments (the Chinese and Polish government) first. After the consultation, we were advised to focus on the Asia-Europe break bulk liner service' (PolcoSM5).

Whether there is any institutional influence in an international collaboration - or how much often depends on the industrial features of the international collaboration. For example, if the collaboration is based in the industries of infrastructure, transportation, automobile and telecommunication in China, it is highly likely that the government either influences or ultimately controls the integration of unilaterally ascribed collective identity.

Solidification of Collective Identity. The shift of (re)identified MACICs to crystallized ones is achieved by the solidification of collective identity. This contributes to the stability of the common sense of 'we-ness'. Partners tend to de-emphasize the issues of cultural distance to maintain congruence in the form of crystallized MACICs. For example, Shelstom utilized its logo both domestically and internationally, to promote exceptional integrity of brand image. The identified MACIC 'JV' in 'break bulk liner service' became crystallized through the representation of the company image:

'...The logo of Shelstom was also widely used within the Company from the shipping port to uniforms and business cards ... Many leaders from the Chinese and Polish central governments often visited Shelstom. Shelstom made full use of these opportunities to promote the company image...Dozens of central and local news agents, radio and TV stations (in China) published and broadcasted Shelstom's company articles and documentaries' (Company reports on Shelstom's development published in both 2005 and 2015).

Solidification of collective identity can thus be promoted through the widespread usage of collective identity images such as the company logo, uniforms and business cards which contributes to the participants' sense of belongingness to the collaboration. Mass media such 
as newspapers, TV and radios can also be used as powerful tools to solidify the image of collective identity to the external environment.

Two other forces appear to be often influential in the solidification process. The first is institutional. For example, because of the political imperatives behind the formation of the identified MACICs between Chinco3 and Polco, the institutional force from the Chinese and Polish government seemed to influence the management practice in Shelstom and the shift of identified MACICs to crystallized ones:

'After the Cultural Revolution, the Chinese central government gave an order: because the Polish partner contributed significantly to China's shipping development, Shelstom should be maintained at the same scale...Until now, there are about 20 vessels in Shelstom, similar as before. So the development scale has been maintained. We can’t expand Shelstom too much or it may become a major competitor to our parent company' (Chinco3GM1).

Especially after the Cultural Revolution, China was predominantly a centrally planned economy with ultimate decision-making and control from the central and local government. Even though China changed to a market economy, the institutional influence is still prevalent in many industries, as mentioned earlier.

The other force for solidification identified in the data is trust. A trusting relationship between partners may help them build confidence about the counterparts' future behavior which will be in favor of stabilizing their collaborative relationship:

'The trust should be very deep. If it's not deep, we'll be in a very difficult situation. We almost can't achieve anything...To be a good company, it aims to achieve stableness. Our company has good structural regulations. Besides it has a solid trusting relationship between partners' (PolcoGM3). 
Reformation of Collective Identity. Collective identity is not a static property but fluid and capable of change giving rise to the reformation of collective identity. This enables partners to change the existing crystallized MACICs either separately or jointly in order to reform the nature of the collaborative relationship and practice substantially. Separate change of crystallized MACICs involves at least one partner's proposing the newly re-identified UACICs - such as a change of equity share among partners and/or a new development area for the international collaboration - to other partners; joint change of crystallized MACICs concerns the pursuit of re-identified MACICs from all collaborating partners involved. Separate change differs from joint change in that no agreement has been achieved between partners on whether and how the crystallized MACICs should be replaced. Joint change tends to be more effective than separate change because partners have already achieved agreement on how the new collective identity should be mutually constructed without the necessity of undergoing the process of negotiation and/or integration of unilaterally ascribed collective identity.

On the one hand, the separate change of crystallized MACICs is often triggered by at least one partner's shifted aims toward the collaborative agenda. For instance, in Gelstom, as explained earlier, the MACIC 'partnership' in 'product applications' and 'customer services' had become crystallized by Britco and Chinco1 for more than 20 years until 2005. However, this MACIC was replaced by Britco who proposed a newly re-identified UACIC 'equity JV' to Chinco1 largely because of Britco's shifted aim which was to expand the market in China through sharing the physical manufacturing plant with Chinco1. There were substantial differences between the two collaborating forms. The 'partnership' form led Britco to build contractual agreements with Chincol on the sale of their products to China, which was 
relatively limited access to the Chinese market. By contrast, the JV form gave Britco more economies of scale which led to the extension of Britco's current collaborative capacity.

On the other hand, the joint change of crystallized MACICs is often triggered by the realization of the common aim(s) shared by all partners toward the international collaboration. For example, according to a senior manager of Chinco2 in Telstom, the company image, which was represented by the 'ready-mix delivery trucks' painted with 'pink and red' became a crystallized MACIC to both the partners and external environment. This MACIC defeated the conventional public image of a ready-mix truck which was deemed as 'dirty and grey in color'. Because of Telstom's high quality of product and customer service, most of the competitors in Tianjin followed Telstom's examples, which subsequently raised the standards of the whole ready-mix industry. In order to realize the common aim of maintaining the forerunner position in the Tianjin market, Britco and Chinco2 jointly created a re-identified MACIC 'new ready-mix materials and delivery service'. This was largely different from the crystallized MACIC because the customers were changed from building companies to families:

'...The competition from other companies can become a motivation for us (Ausco and Chinco2) to develop...we are developing new ready-mix materials and delivery service...We had a couple of meetings on the design of new ready-mix products which can be sold through supermarkets for family use...' (Chinco2SM2).

Issues of cultural distance are addressed differently by participants in the separate and joint change situations. Cultural distance is often highlighted as one of the major factors that impact on separate change. For instance, in Gelstom, a senior manager deemed different perceptions of time to be a major factor that hindered Britco and Chincol's members' in 
achieving mutual agreement on Britco's replacement of the crystallized MACIC 'partnership' with a newly re-identified UACIC 'JV':

'You see the two sets of management teams being in conflict: they want to go this way, we want to go that way...It is a perception of time, you know, the Chinese perception of time compared to the British perception of time: whenever they want to move fast, we want to move slow. Whenever they want to move slow, we want to move fast...' (BritcoSM1). By contrast, participants tend to downplay the influence of cultural distance in the joint change situation. Although there are cultural differences, participants may assimilate themselves into the culture of counterpart(s); this contributes to the development of reidentified MACICs. In Telstom, a senior manager deemphasized the role of cultural distance between Ausco and Chinco2 because of Ausco members' cultural assimilation. This was regarded as helpful for the joint change of crystallized MACIC to a newly re-identified one because of partners' similar cultural orientations:

'I think people can be assimilated...our general manager (from Ausco) has stayed in China for ten years. He has adapted himself to the Chinese culture...for the future development of Telstom, we agreed to figure out how to increase our product portfolios and reduce the cost...' (Chinco2SM4)

Deconstruction of Collective Identity. Despite its cyclic and enduring nature, collective identity work can be terminated by partners. The deconstruction of collective identity means the disintegration of a collaborative relationship. This often causes the (re)identified MACICs - and even those that have been crystallized - to become disidentified during the lifespan of an international collaboration. Specifically, the shift from (re)identified to dis-identified MACICs tends to be a result of the discursive construction of cultural distance between partners. The discursive construction may begin with one member's 
ascription of cultural distance. It can become more consolidated when more members are involved in the production and reproduction of the collective beliefs toward the incompatibility between partners' values and/or management practice. For instance, as explained earlier, in Gelstom, the senior manager from Britco discursively positioned the collectivistic (Chinco1) versus individualistic (Britco) cultural distance as the main driver for the termination of the JV talk. This discursive construction was affirmed by other managers in Britco through minutes of meetings and company reports, which gave rise to the withdrawal of the JV talk.

The shift from crystallized to dis-identified MACICs tends to be triggered by partners' loss of common aims which often emerges from the communication process (such as via 'meetings') and is embodied by the termination of contractual arrangements. For instance, in the Telstom case, according to a senior manager's interview comment and the company's strategic report published in 2015, Telstom had maintained the crystallized MACIC 'long partnerships' with several construction companies. However, this MACIC was once dis-identified by Telstom's partners at joint meetings due to the absence of the common aims with Telstom concerning the transaction of ready-mix products. The collaborative relationship came to an end when Telstom and the partners jointly terminated the contracts: 'We (Telstom) had long partnerships with several construction companies because of our superior quality ready-mix products...Two of the companies left us about a year ago because of the strategic shift to other industries...They had meetings with us and we cancelled the contracts together' (Chinco2SM6). 


\section{Discussion and Conclusions}

Theoretically, the research presented in this article advances the understanding of discursive collective identity formation in the field of organizational identity (Vaara et al., 2005; Vaara et al., 2003; Ybema, 2010). To date, scholars have investigated collective identity formation, for example, in the form of social movements, organizational fields, or new markets from an institutional perspective of organizational identity (e.g., Navis and Glynn, 2010; Wry et al., 2011). Such an institutional perspective emphasizes the salience of claims that organizational members make about who they are as a collective (Whetten, 2006). By adopting a discursive perspective of identity, this research advances the understanding of the "deeper processes involved in the emergence of these claims" (Patvardhan et al., 2015: 425).The various states and processes identified from this research, which are exemplified by partners' maneuvering the different discursive resources of CICs (Zhang and Huxham, 2009), capture the fluid and fragmented nature of collective identity that is produced and reproduced in partners' everyday collaborative practice. The state changes of UACICs and MACICs also unveil the dynamic processes of sensemaking and sensebreaking of organizational members (Corley and Gioia, 2004; Patvardhan et al., 2015), which further strengthens the becoming view of organization (Tsoukas and Chia, 2002). Collective identity may at times appear to be stable, but this stability is a consequence of sustained discursive practice among partners, rather than "an inherent property of the organization that exists outside its current membership and organizing practices" (Koschmann, 2013: 83).

This research also extends the studies of collective identity formation (Beech and Huxham, 2003; Ellis and Ybema, 2010; Hardy et al., 2005; Patvardhan et al., 2015; Ybema et al., 2012) to a transnational business collaboration context. The use of cultural distance 
narratives in partners' discursive practice offers an empirically grounded understanding of the triggers that drive partners to form, repair, maintain, strengthen, or revise the collective identity (Hardy et al., 2005; Sveningsson and Alvesson, 2003). Based on the investigation of collective identity work in an international collaboration between a Dutch voluntary organization and their Southern partners, Ybema et al. (2012) emphasize that cultural differences in association with the usual "us-and-them" talk can be downplayed by collaborating partners in the discursive construction of collective identity. This view is further supported by the findings from this research in that the formation and crystallization of MACICs is often accompanied by partners' avoidance of cultural distance narratives. The findings from this research also suggest that language interpreters and business consultants, who can be deemed as boundary bricolage (Ellis and Ybema, 2010), play a mediating role in partners' mutual cultural understanding and collective identity construction. These groups of people contribute to the state shifts of the UACICs and MACICs, which leads to the (re)formation of collective identity in international collaborations. Additionally, the research findings suggest that collective identity can be shattered, resulting in the termination of partners' collaborative relationships.

Moreover, this research sheds light on the processual understanding of international collaborative practice (Doz, 1996; Vaara et al., 2005; Vaara et al., 2003; Ybema et al., 2012). Studies on international collaborations have been dominated by quantitative research with hypotheses testing of collaboration performance and there has thus been relatively little attention paid to the processual factors that contribute to the performance outcome. Stereotypes toward group identities (in- and out-group differentiations) are prevalent in partners' interaction and impact on the collaborative performance (Ashforth and Mael, 1989; 
Pearce, 2000; Salk and Shenkar, 2001). The qualitative case investigation adopted in this research develops theoretical and empirical insights into why and how the salience of group identity occurs in international collaborations through the identification of the two inseparable elements constituting the cyclic and enduring process of collective identity work. Our findings support the views of Vaara et al. (2003) on the importance of language in the subjectivity construction processes in multinational settings which involve not only group but also national and international identities and subjectivities. It can be argued that partners' subjectivity construction can be mediated by a particular group of members who are competent in cross-cultural communication, for example, language interpreters and consulting professionals from both within and outside the partnering organizations.

Furthermore, this research develops theoretical and empirical insights into the conceptualization of the relations between culture and identity (Hatch and Schultz, 2002). Our findings suggest that cultural distance can be discursively used by partners to justify the various states of collective identity development. This complements Hatch and Schultz's (2002) view of identity as a way of expressing cultural understandings. Our empirical work extends their approach to culture and identity from the organizational to national level. It highlights the active role of organizational members in using cultural distance narratives to express their identity beliefs. For instance, the participants from Chinco 2 strategically suppressed or utilized the cultural narratives of Chinese collectivism to reconstruct or deconstruct the collective identity with their partners representing individualistic cultures. This discursive view of cultural claims offers more processual insights in comparison with the deterministic view of culture in shaping organizational members' behaviors (Hofstede, 1980; Trompenaars and Hampden-Turner, 1997). 
Practically, this research can significantly inform the management of international collaborations in two ways. Firstly, the identity perspective on interpreting complexity in collaboration can facilitate strategic change and interventions. The model of collective identity work developed from this research helps raise participants' awareness of identity issues in the day-to-day practice of making collaboration happen. As mentioned above, practitioners may disentangle the complex web of collaborative situations through reflecting on multi-level and multi-party collective identity construction processes and the subsequent enactment of identity. In this way, they may determine the key elements either in the collaborative situations or in the identity construction processes. Accordingly, they may foresee potential intervention opportunities and create change. Secondly, the identity perspective on international collaborations helps practitioners enhance their understanding of the dilemmas faced by different parties across national boundaries. Hence, this processual focus could lead to in-depth explanations of consequential dilemmas, such as communication, leadership and others, in international collaborative settings.

While this study provides important insights into collective identity work in international collaborative settings, it has limitations. Firstly, constraints upon the time available for the primary data collection led to it being conducted only in one time period (i.e., 2005-2006) and in one geographical region of the organizations involved in the collaborations rather than all of them. That is, the interview and participant observation data were mainly collected only from the British parent organization in the Gelstom case, and only from the JVs themselves rather than the parent organizations in the Telstom and Shelstom cases. Despite these constraints upon the time and location, this research has ensured validity (Pratt, 2000) and trustworthiness (Lincoln and Guba, 1985) through the rigorous data coding 
and analysis procedures. As aforementioned, email communications were maintained with the interview respondents throughout the data collection process between 2005 and 2016, which helped corroborate the research findings and frameworks developed. Alternative longitudinal secondary data - for instance, organizational reports, memoranda of understanding, and other relevant materials - were also collected from 2005 to 2016 to triangulate the insights gathered from the primary data. Secondly, in terms of the collaboration type, the selected cases were all in business sectors. The industrial feature of the business collaborations across national boundaries may constrain the transferability of the findings to other types of collaborative relationship, such as an international public-private partnership. However, it is recognized that the case study approach required certain compromises between maximizing the quantity and type of cases which could be integrated, and being able to conduct the empirical data collection and analysis effectively.

Thirdly, and similarly, the cases all involved just two organizations, rather than being three or multi-party collaborations. Fourthly, all of the cases investigated in this study involved a Chinese partner and the Chinese parent companies were all state-owned enterprises. Although characteristics idiosyncratic to Chinese collaborative relationships, such as central governmental control (Williamson, 2003), might put a particular spin on the research results, this research aims to form the concepts sufficiently generically to take account of the unique and idiosyncratic features that impact the shape and outcome of managerial processes in any national environment (Shenkar and Yan, 2002). Finally, there was difficulty in conducting observational research in one of the cases (Gelstom) due to the managerial group's concerns about confidentiality in that research setting, and this may have introduced certain bias in the data analysis. However, the other two cases were completely 
accessible and the researcher was able to collect naturally occurring data using the unhampered observational research method. These data from Gelstom may serve as complementary findings to support the general discussion of the research themes.

In terms of future research, it is suggested that the conceptual framework developed from this research could be further examined in other types of international collaborations such as public sector collaboration or public-private collaboration. In addition, the more detailed examination of process dynamics could lead to in-depth explanations of consequential dilemmas, such as trust, power, and communication in international collaborative settings. With reference to collaborative practice, future studies could be conducted using action research to examine the dynamics of identity in the collaborative settings with the aim of helping practitioners achieve collaborative advantage (Huxham and Vangen, 2000). Interventions can be utilized by both researchers and practitioners to change the perceptions of CICs in the research settings in order to build and reinforce the collective identity established in international collaborative practice.

\section{Notes}

Unless otherwise indicated the following codes imply interview responses: BDM-business development manager; GM-general manager; OM-operations manager; MM-marketing manager. SM-senior manager. 


\section{References}

Albert S, Ashforth BE and Dutton JE (2000) Organizational identity and identification:

Charting new waters and building new bridges. Academy of Management Review 25: 13-17.

Albert S and Whetten DA (1985) Organizational identity. In: Cummings LL and Staw BM (eds) Research in Organizational Behavior. Greenwich, CT: JAI Press, 263-295.

Alvesson M (2010) Self-doubters, strugglers,storytellers, surfers and others: Images of selfidentities in organization studies. Human Relations 63: 193-217.

Alvesson M and Kärreman D (2007) Unraveling HRM: Identity, ceremony, and control in a management consulting firm. Organization Science 18: 711-723.

Alvesson $\mathrm{M}$ and Willmott $\mathrm{H}$ (2002) Identity regulation as organizational control: Producing the appropriate individual. Journal of Management Studies, 39(5): 619-644. 5: 619644.

Ashforth BE and Mael F (1989) Social identity theory and the organisation. Academy of Management Review 14: 20-39.

Beech N (2011) Liminality and the practices of identity reconstruction. Human Relations 64: 285-302.

Beech N and Huxham C (2003) Cycle of identity formation in interorganizational collaboration. International Studies of Management and Organization 33: 28-52.

Brannen MY and Salk JE (2000) Partnering across borders: Negotiating organizational culture in a German-Japanese joint venture. Human Relations 53: 451-487.

Brewer JD and Hunter A (1989) Multimethod research: A synthesis of styles, Newbury Park, CA: Sage Publications.

Brislin RW (1986) The wording and translation of research instruments. In: Lonner WJ and Berry JW (eds) Field methods in cross-cultural research. Beverly Hills CA: Sage, 137-164.

Brown A (2006) A narrative approach to collective identities. Journal of Management Studies 43: 731-753.

Brown AD and Humphreys M (2002) Nostalgia and the narrativization of identity: a Turkish case study. British Journal of Management 13: 141-159. 
Cerulo KA (1997) Identity construction: New issues, new directions. Academy Review of Sociology 23: 385-409.

Collinson DL (2003) Identities and insecurities: Selves at work. Organization 10: 527-547.

Corley KG and Gioia DA (2004) Identity ambiguity and change in the wake of a corporate spin-off. Administrative Science Quarterly 49: 173-208.

Davis JP, Eisenhardt KM and Bingham CB (2007) Developing theory through simulation methods. Academy of Management Review 32: 480-499.

Denzin NK and Lincoln YS (1998) Strategies of qualitative inquiry. London: Sage Publications.

DiMaggio PJ and Powell WW (1983) The iron cage revisited: Institutional isoporphism and collective ratinoality in organizational fields. Americal Sociological Review 48: 147160.

Doz YL (1996) The evolution of cooperation in strategic alliances: Initial conditions or learning processes? Strategic Management Journal 17: 55-83.

Eisenhardt KM (1991) Better stories and better constructs: The case for rigor and comparative logic. Academy of Management Review 16: 620-627.

Eisenhardt KM and Graebner ME (2007) Theory Building from Cases: Opportunities and Challenges. Academy of Management Journal 50: 25-32.

Ellis N and Ybema S (2010) Marketing identities: Shifting circles of identification in interorganizational relationships. Organization Studies 31: 279-305.

Fiol CM and Romanelli E (2012) Before Identity: The Emergence of New Organizational Forms. Organization Science 23: 597-611.

Fiol MC (2002) Capitalizing on paradox: The role of language in transforming organizational identities. Organization Science 13: 653-666.

Giddens A (1991) Modernity and self-identity, Cambridge: Policy Press.

Glynn MA (2008) Beyond constraint: How institutions enable identities. In: Greenwood R,

Oliver C, Sahlin K, et al. (eds) Handbook of organizational

institutionalism. Los Angeles, CA: Sage, 413-430.

Hall ET (1976) Beyond culture, Garden City, NY: Anchor Press/Doubleday.

Hammersley M and Atkinson P (1983) Ethnography: Principles in Practice, London: Tavistock Publications Ltd. 
Hardy C, Lawrence TB and Grant D (2005) Discourse and collaboration: The role of conversations and collective identity. Academy of Management Review 30: 58-77.

Hatch MJ and Schultz M (2002) The dynamics of organizational identity. Human Relations 55: 989-1018.

He HW and Brown AD (2013) Organizational Identity and Organizational Identification: A Review of the Literature and Suggestions for Future Research. Group \& Organization Management 38: 3-35.

Hofstede G (1980) Culture's consequences: International differences in work-related values, Beverly Hills, California: Sage.

Hoon-Halbauer SK (1999) Managing relationships within Sino-foreign joint ventures. Journal of World Business 34: 344-399.

Humphreys M and Brown AD (2002) Narratives of organizational identity and identification: A case study of hegemony and resistance. Organization Studies 23: 421-447.

Huxham C and Vangen S (2000) Leadership in the shaping and implementation of collaboration agendas: how things happen in a (not quite) joined up world. Academy of Management Journal 43: 1159-1175.

Huxham C and Vangen S (2005) Managing to collaborate:The theory and practice of collaborative advantage, London: Routledge.

Ibarra H, Kilduff M and Tsai W (2005) Zooming in and out: Connecting individuals and collectivities at the frontiers of organizational network research. Organization Science 16: $359-371$.

Jones S (2004) Depth interviewing. In: Seale C (ed) Social research methods. London: Routledge, 257-260.

Junker BH (2004) The field work situation: Social roles for observation. In: Seale C (ed) Social research methods: A reader. London: Routledge, 221-225.

Koschmann MA (2013) The communicative constitution of collective identity in interorganizational collaboration. Management Communication Quarterly 27: 61-89.

Li J, Xin K and Pillutla M (2002) Multi-cultural leadership teams and organizational identification in international joint ventures. International Journal of Human Resource Management 13: 320-337.

Lincoln YS and Guba EG (1985) Naturalistic inquiry.Beverly Hills, CA: Sage. 
Locke K (1996) Rewriting the Discovery of Grounded Theory after 25 years? Journal of Management Inquiry 5: 239-245.

Luo Y (2002) Building trust in cross-cultural collaborations: Towards a contingency perspectives. Journal of Management 28: 669-694.

Maanen JV (1979) The fact of fiction in organizational ethnography. Administrative Science Quarterly 24: 539-550.

Maguire S and Hardy C (2005) Identity and collaborative strategy in the Canadian HIV/AIDS treatment domain. Strategic Organization 3: 11-45.

Navis C and Glynn MA (2010) How New Market Categories Emerge: Temporal Dynamics of Legitimacy, Identity, and Entrepreneurship in Satellite Radio, 1990-2005. Administrative Science Quarterly 55: 439-471.

Öberg C (2016) What creates a collaboration-level identity? Journal of Business Research 69: 3220-3230.

Park SH and Luo Y (2001) Guanxi and organizational dynamics: organizational networking in Chinese firms. Strategic Management Journal 22: 455-477.

Patvardhan SD, Gioia DA and Hamilton AL (2015) Weathering a meta-level identity crisis: Forging a coherent collective identity for an emerging field. Academy of Management Journal 58: 405-435.

Pearce RJ (2000) The general manager's perspective on how factionalism can impact the behaviors and effectiveness of top managers inside a shared management joint venture. Journal of Management and Governance 4: 189-206.

Powell EE and Baker T (2017) In the beginning: Identity processes and organizing in multifounder nascent ventures. Academy of Management Journal 60: 2381-2414.

Pratt MG (2000) The good, the bad, and the ambivalent: Managing identification among Amway distributors. Administrative Science Quaterly 45: 456-493.

Pratt MG (2003) Disentangling collective identities. In: Polzer J, Mannix E and Neale M (eds) Identity Issues in Groups: Research in Managing Groups and Teams. Stamford, CT: Elsevier Science, 161-188. 
Rao H, Davis GF and Ward A (2000) Embeddedness, Social Identity and Mobility: Why Firms Leave the NASDAQ and Join the New York Stock Exchange. Administrative Science Quarterly 45: 268-292.

Ravasi D and Schultz M (2006) Responding to organizational identity threats: Exploring the role of organizational culture. Academy of Managemement Journal 49: 433-458.

Rometsch M and Sydow J (2006) On identities of networks and organizations - The case of Franchising. In: Kornberger M and Gudergan S (eds) Only connect: Neat words, networks and identities. Slovenia: Korotan Ljubljana, Slovenien, 19-47.

Salk JE and Brannen MY (2000) National culture,networks, and individual influence in a multinational management team. Academy of Management Journal 43: 191-202.

Salk JE and Shenkar O (2001) Social identities in an international joint venture: An exploratory case study. Organization Science 12: 161-178.

Schaffer BS and Riordan CM (2003) A review of cross-cultural methodologies for organizational research: A best-practices approach. Organizational Research Methods 6: $169-215$.

Shenkar O and Yan A (2002) Failure as a consequence of partner politics: Learning from the life and death of an international cooperative venture. Human Relations 55: 565-601.

Silverman D (1993) Interpreting qualitative data: Methods for analysing talk, text and interaction, London: Sage.

Sirmon DG and Lane PJ (2004) A model of cultural differences and international alliance performance. Journal of International Business Studies 35: 306-320.

Sveningsson S and Alvesson M (2003) Managing managerial identities: Organizational fragmentation, discourse and identity struggle. Human Relations 56: 1163-1194.

Thomas R and Linstead A (2002) Losing the plot? Middle managers and identity. Organization 9: 71-93.

Thornborrow T and Brown AD (2009) 'Being Regimented': Aspiration, discipline and identity work in the British Parachute Regiment. Organization Studies 30: 355-376.

Trompenaars F and Hampden-Turner C (1997) Riding the wave of culture: Understanding cultural diversity in global business, New York: McGraw-Hill.

Tsoukas H and Chia R (2002) On organizational becoming: rethinking organizational change. Organizational Science 13: 567-582. 
Vaara E, Tienari J, Piekkari R, et al. (2005) Language and the circuits of power in a merging multinational corporation. Journal of Management Studies 42: 595-623.

Vaara E, Tienari J and Säntti R (2003) The international match: Metaphors as vehicles of social identity-building in cross-border mergers. Human Relations 56: 419-451.

van Marrewijk A (2010) Situational construction of Dutch-Indian cultural differences in global IT projects. Scandinavian Journal of Management 26: 368-380.

Vangen S (2017) Developing Practice-Oriented Theory on Collaboration: A Paradox Lens. Public Administration Review 77: 263-272.

Watson TJ (2008) Managing identity: Identity work, personal predicaments and structural circumstances. Organization 15: 121-143.

Whetten DA (2006) Albert and Whetten Revisited: Strengthening the Concept of Organizational Identity. Journal of Management Inquiry 15: 219-234.

Williamson A (2003) The Chinese business puzzle:How to work more effectively with Chinese cultures, Oxford: How To Books Ltd.

Wry T, Lounsbury M and Glynn MA (2011) Legitimating nascent collective identities: Coordinating cultural entrepreneurship. Organization Science 22: 449-463.

Yan A and Gray B (1994) Bargaining power, management control, and performance in United States-China joint ventures: A comparative case study. Academy of Management Journal 37: 1478-1517.

Ybema S (2010) Talk of change: Temporal contrasts and collective identities. Organization Studies 31: 481-503.

Ybema S and Byun H (2009) Cultivating cultural differences in asymmetric power relations. International Journal of Cross Cultural Management 9: 339-358.

Ybema S, Vroemisse M and van Marrewijk A (2012) Constructing identity by deconstructing differences: Building partnerships across cultural and hierarchical divides. Scandinavian Journal of Management 28: 48-59.

Zhang Y and Huxham C (2009) Identity construction and trust building in developing international collaborations. Journal of Applied Behavioral Science 45: 186-211. 


\section{FIGURE 1: A MODEL OF COLLECTIVE IDENTITY WORK IN INTERNATIONAL}

\section{COLLABORATIONS}

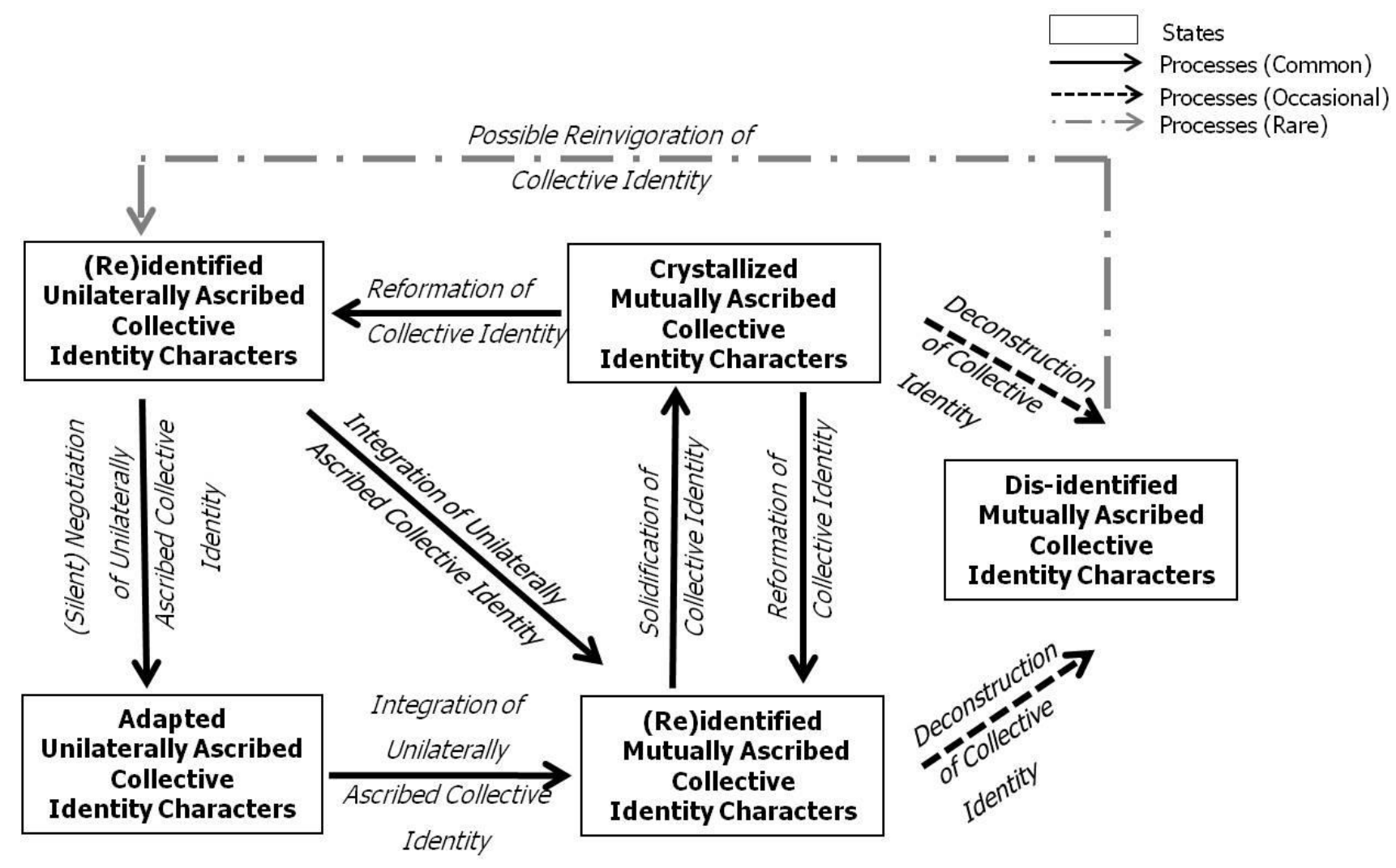


TABLE 1: THEORETICAL PERSPECTIVE ON COLLECTIVE IDENTITY

\begin{tabular}{lll}
\hline Characteristic & Institutional perspective & Discursive perspective \\
\hline Theoretical foundations & Institutional theory & Social constructionism \\
Cofinition of identity & institutional claims, available & collectively shared stories, \\
to members, about central, & for instance, organizational \\
& enduring and distinctive & members' everyday \\
attributes of their & conversations and \\
organization (Ravasi and & organizational websites, \\
Schultz, 2006) & magazines, or historical \\
& & accounts (Brown, 2006, \\
& & p.734).
\end{tabular}


TABLE 2: MULTIPLE DATA SOURCES

\section{Data Sources}

\begin{tabular}{|c|c|c|c|}
\hline Data type & Quantity & Data origin & Time period collected \\
\hline Interviews & $\begin{array}{l}36 \text { (Gelstom: } n=1 \text {; Telstom: } n=19 ; \\
\text { Shelstom: } n=16 \text { ) each lasting } 45 \text { to } 90 \\
\text { minutes }\end{array}$ & $\begin{array}{l}\text { Informants who were top and middle } \\
\text { managers of Gelstom, Telstom and } \\
\text { Shelstom }\end{array}$ & July 2005 - October 2006 \\
\hline $\begin{array}{l}\text { Company annual and } \\
\text { strategic reports }\end{array}$ & $\begin{array}{l}5159 \text { pages (Gelstom: } 2651 \text { pages; } \\
\text { Telstom: } 1232 \text { pages; Shelstom: } 1276 \\
\text { pages) }\end{array}$ & $\begin{array}{l}\text { Informants and corporate } \\
\text { communication }\end{array}$ & July 2005 - August 2016 \\
\hline $\begin{array}{l}\text { Memorandum of } \\
\text { understanding for } \\
\text { collaboration }\end{array}$ & $\begin{array}{l}970 \text { pages (Gelstom: } 426 \text { pages; } \\
\text { Telstom: } 334 \text { pages; Shelstom: } 210 \\
\text { pages) }\end{array}$ & Informants & July 2005 - August 2016 \\
\hline $\begin{array}{l}\text { Participant observational } \\
\text { notes and diaries }\end{array}$ & $\begin{array}{l}\text { Approximately } 112 \text { hours (Telstom: } 56 \\
\text { hours; Shelstom: } 56 \text { hours) }\end{array}$ & $\begin{array}{l}\text { Principal investigator's notes and diaries } \\
\text { from two 7-day participant observations } \\
\text { with one in Telstom and the other in } \\
\text { Shelstom }\end{array}$ & July - August 2005 \\
\hline $\begin{array}{l}\text { Internal email } \\
\text { communication between the } \\
\text { collaborating companies }\end{array}$ & $\begin{array}{l}236 \text { pages (Gelstom: } 96 \text { pages; Telstom: } \\
73 \text { pages; Shelstom: } 67 \text { pages) }\end{array}$ & Informants & July 2005 - August 2016 \\
\hline Company websites & & $\begin{array}{l}\text { Corporate public relations office } \\
\text { materials from Gelstom, Telstom and } \\
\text { Shelstom }\end{array}$ & July 2005 - August 2016 \\
\hline
\end{tabular}


TABLE 3: STATES OF COLLECTIVE IDENTITY DEVELOPMENT

\begin{tabular}{|c|c|c|}
\hline & Features & Linkages to culture \\
\hline $\begin{array}{l}\text { States of collective } \\
\text { identity development }\end{array}$ & $\begin{array}{l}\text { Various forms of CICs } \\
\text { which can be both } \\
\text { unilaterally and mutually } \\
\text { ascribed by partners. }\end{array}$ & $\begin{array}{l}\text { National culture is used as a } \\
\text { discursive resource by } \\
\text { participants to justify the } \\
\text { states of collective identity } \\
\text { development. }\end{array}$ \\
\hline $\begin{array}{l}\text { (Re)identified } \\
\text { unilaterally ascribed } \\
\text { CICs (UACICs) }\end{array}$ & $\begin{array}{l}\text { Achieved by members of } \\
\text { just one of the partners } \\
\text { defining for themselves } \\
\text { the nature of the collective } \\
\text { identity }\end{array}$ & $\begin{array}{l}\text { National cultural attributes } \\
\text { can be used by participants } \\
\text { to justify why UACICs shift } \\
\text { from identified to re- } \\
\text { identified state. }\end{array}$ \\
\hline $\begin{array}{l}\text { Adapted unilaterally } \\
\text { ascribed CICs }\end{array}$ & $\begin{array}{l}\text { Come into place when a } \\
\text { partner changes its } \\
\text { UACICs in order to be } \\
\text { congruent with those from } \\
\text { the counterpart(s) }\end{array}$ & $\begin{array}{l}\text { Cultural distance can be } \\
\text { discursively used by } \\
\text { partners to construct how } \\
\text { their (re)identified UACICs } \\
\text { are divergent and why } \\
\text { adapted UACICs are needed } \\
\text { in developing the } \\
\text { collaborative relationship. }\end{array}$ \\
\hline $\begin{array}{l}\text { (Re)identified mutually } \\
\text { ascribed CICs } \\
\text { (MACICs) }\end{array}$ & $\begin{array}{l}\text { Concern the congruence of } \\
\text { certain UACICs between } \\
\text { collaborating partners }\end{array}$ & $\begin{array}{l}\text { Cultural distance tends to be } \\
\text { downplayed by partners } \\
\text { given that congruence is an } \\
\text { essential feature for the } \\
\text { merging of partners' } \\
\text { UACICs. }\end{array}$ \\
\hline $\begin{array}{l}\text { Crystallized mutually } \\
\text { ascribed CICs }\end{array}$ & $\begin{array}{l}\text { Refer to a stable collective } \\
\text { image that participants can } \\
\text { attach themselves to, } \\
\text { which helps to strengthen } \\
\text { the participants' sense of } \\
\text { belongingness. }\end{array}$ & $\begin{array}{l}\text { Cultural distance is } \\
\text { extenuated by partners to } \\
\text { maintain the congruence in } \\
\text { the form of crystallized } \\
\text { MACICs. }\end{array}$ \\
\hline $\begin{array}{l}\text { Dis-identified mutually } \\
\text { ascribed CICs }\end{array}$ & $\begin{array}{l}\text { Not part of the cyclic } \\
\text { process of collective } \\
\text { identity work and they are } \\
\text { no longer going to be } \\
\text { (re)identified and adapted. }\end{array}$ & $\begin{array}{l}\text { Collectivism versus } \\
\text { individualism tends to be } \\
\text { used by collaborating } \\
\text { participants in the discursive } \\
\text { construction of dis- } \\
\text { identified MACICs. }\end{array}$ \\
\hline
\end{tabular}


TABLE 4: PROCESSES OF COLLECTIVE IDENTITY DEVELOPMENT

\begin{tabular}{|c|c|c|}
\hline & Features & Linkages to culture \\
\hline $\begin{array}{l}\text { Processes of collective } \\
\text { identity development }\end{array}$ & $\begin{array}{l}\text { Manifested by } \\
\text { (re)construction and } \\
\text { deconstruction of } \\
\text { collective identity }\end{array}$ & $\begin{array}{l}\text { Collaborating participants } \\
\text { actively maneuver the } \\
\text { discursive resources of } \\
\text { cultural distance to express } \\
\text { their identity beliefs. }\end{array}$ \\
\hline $\begin{array}{l}\text { (Silent) negotiation of } \\
\text { unilaterally ascribed } \\
\text { collective identity }\end{array}$ & $\begin{array}{l}\text { Partners negotiate and } \\
\text { change their divergent } \\
\text { (re)identified UACICs to } \\
\text { adapted ones so as to be } \\
\text { more nearly congruent } \\
\text { with those proclaimed by } \\
\text { their counterparts and vice } \\
\text { versa; it can be overt or } \\
\text { silent }\end{array}$ & $\begin{array}{l}\text { Language interpreters and } \\
\text { business consultants often } \\
\text { play a mediating role in } \\
\text { partners' mutual cultural } \\
\text { understandings and facilitate } \\
\text { partners' change of } \\
\text { (re)identified UACICs to } \\
\text { adapted ones. }\end{array}$ \\
\hline $\begin{array}{l}\text { Integration of } \\
\text { unilaterally ascribed } \\
\text { collective identity }\end{array}$ & $\begin{array}{l}\text { The process of partners } \\
\text { merging their adapted or } \\
\text { (re)identified UACICs, to } \\
\text { become (re)identified } \\
\text { MACICs }\end{array}$ & $\begin{array}{l}\text { High- and low- context } \\
\text { cultural difference is } \\
\text { discursively used by partners } \\
\text { to differentiate the use of } \\
\text { meetings and social events in } \\
\text { the integration process. }\end{array}$ \\
\hline $\begin{array}{l}\text { Solidification of } \\
\text { collective identity }\end{array}$ & $\begin{array}{l}\text { The process of partners } \\
\text { shifting (re)identified } \\
\text { MACICs to crystallized } \\
\text { ones; It contributes to the } \\
\text { stability of partners' } \\
\text { common sense of 'we- } \\
\text { ness' in an international } \\
\text { collaboration. }\end{array}$ & $\begin{array}{l}\text { Cultural distance tends to be } \\
\text { de-emphasized by partners } \\
\text { compared to the factors of } \\
\text { institutional force and } \\
\text { partners' mutual trust. }\end{array}$ \\
\hline $\begin{array}{l}\text { Reformation of collective } \\
\text { identity }\end{array}$ & $\begin{array}{l}\text { Partners change the } \\
\text { existing crystallized } \\
\text { MACICs either separately } \\
\text { or jointly in order to } \\
\text { reform the nature of the } \\
\text { collaborative relationship } \\
\text { and practice substantially. }\end{array}$ & $\begin{array}{l}\text { Issues of cultural distance } \\
\text { seem to be addressed } \\
\text { differently by participants } \\
\text { between the separate (being } \\
\text { highlighted) and joint change } \\
\text { (being downplayed) of } \\
\text { crystallized MACICs. }\end{array}$ \\
\hline $\begin{array}{l}\text { Deconstruction of } \\
\text { collective identity }\end{array}$ & $\begin{array}{l}\text { Disintegration of the } \\
\text { collaborative relationship } \\
\text { which often ceases to be } \\
\text { strong enough to continue. }\end{array}$ & $\begin{array}{l}\text { Cultural distance (e.g., } \\
\text { individualism versus } \\
\text { collectivism) and lack of } \\
\text { common aims are } \\
\text { discursively used by partners } \\
\text { in the deconstruction process. }\end{array}$ \\
\hline
\end{tabular}

